\title{
Promover la lectura mejora el desarrollo del lenguaje en los niños
}

Literacy Promotion in Primary Care Pediatrics: Can We Make a Difference? High P, LaGasse L, Becker S y col. Pediatrics 2000; 105 : 927-934.

\section{Objetivo}

Evaluar el efecto de la promoción de la lectura en los niños sanos sobre el lenguaje de los niños y las actitudes y comportamiento de los padres.

\section{Diseño}

Estudio prospectivo, aleatorizado en dos ramas: intervención vs. cuidados habituales.

\section{Lugar}

Centros de pediatría ambulatoria de una población urbana de bajos ingresos, multiétnica, en EE.UU

\section{Pacientes}

\section{Intervención}

Se realizó una encuesta inicial sobre hábitos de lectura. Las 106 familias asignadas a la rama intervención recibieron: libros adecuados para la edad del lactante, un folleto explicativo de los beneficios para el niño de disfrutar e interactuar con libros y una guía de promoción de la lectura. Las 99 familias asignadas al grupo control recibieron consultas de rutina sin libros ni folletos. Un mes después de haber completado 3 visitas o cuando el niño cumpliera 22 meses se realizó la encuesta final.

\section{Medición de resultados principales}

La encuesta final evaluaba: días por semana que los padres leían libros con su hijo y noches por semana que los padres compartían libros con sus hijos. Se preguntaban las actividades favoritas de sus hijos y las que a ellos les gustaba hacer con sus hijos. Si

leer libros estaba dentro de las favoritas o si leían por lo menos 6 noches por semana, se las consideraba familias con orientación a la lectura para niños (FOLN). También se evaluaban los hábitos de lectura de los padres. Una versión modificada del test de Mc Arthur (mide desarrollo comunicativo) fue realizada. Se seleccionaron 50 palabras de la lista de Mc Arthur presentes en los libros y 50 palabras que no estuvieran en los libros y se desarrolló un puntaje de 0 a 100 para el lenguaje expresivo y receptivo de los niños.

\section{Resultados}

La entrevista final pudo realizarse en 77 de las 105 familias del grupo intervención $(79 \%$ ) y 76 de las 99 familias controles (75 $\%)$. Aunque las familias eran similares al inicio del estudio, las del grupo intervención leyeron más frecuentemente en voz alta a sus hijos, con más entusiasmo para leer juntos y más libros para niños en el hogar. Aumentó la lectura como una de las tres actividades favoritas de los niños y de las actividades compartidas entre padres e hijos. También aumentó el porcentaje de FOLN. En las familias del grupo intervención también se observó una diferencia significativa en el desarrollo del lenguaje de los niños deambuladores mayores (18 a 25 meses), sin hallar diferencias en los deambuladores menores (13 a 17 meses).

Se observó que la lectura en voz alta de padres a hijos fue el mejor predictor del beneficio de la intervención.

\section{Conclusión}

La provisión de libros, material educativo que estimule compartir la lectura entre padres y lactantes como parte de la consulta pediátrica de niño sano, modifica favorablemente la actitud de la familia para la lectura a los niños y aumenta el lenguaje expresivo y receptivo en niños deambuladores mayores.

\begin{tabular}{|c|c|c|c|}
\hline Resultados prineipales evaluados & Familias control & Familias intervención & Valor de $\mathbf{P}$ \\
\hline Los padres leen a los hijos 3 o mas días $\mathrm{x}$ semana & $46 \%$ & $78 \%$ & $<0.001$ \\
\hline Padres e hijos comparten libros mas de 6 noches $\mathrm{x}$ semana & $13 \%$ & $32 \%$ & 0.006 \\
\hline Es una de las tres actividades favoritas de los niños & $12 \%$ & $27 \%$ & 0.02 \\
\hline Es una de las 3 actividades favoritas compartidas & $33 \%$ & $57 \%$ & 0.003 \\
\hline FOLN (familias con orientación a la lectura para niños) & $43 \%$ & $68 \%$ & 0.003 \\
\hline $\begin{array}{r}\text { Mc Artur Vocabulario expresivo (100 palabras) } 13-17 \text { meses } \\
18-25 \text { meses }\end{array}$ & $\begin{array}{l}40.5 \\
38.3\end{array}$ & $\begin{array}{l}45.7 \\
54.8\end{array}$ & $\begin{array}{c}0.37 \\
0.004\end{array}$ \\
\hline $\begin{aligned} & \text { Mc Artur Vocabulario receptivo (100 palabras) } 13-17 \text { meses } \\
& 18-25 \text { meses }\end{aligned}$ & $\begin{array}{l}13.5 \\
32.1\end{array}$ & $\begin{array}{l}17.5 \\
0.10\end{array}$ & $\begin{array}{l}7.9 \\
0.01\end{array}$ \\
\hline
\end{tabular}

Fuente de financiamiento: Brown University School of Medicine, y Department of Health and Human Services, Maternal and Child Health Bureau.

\section{Comentario}

El pediatra habitualmente incluye en la consulta de niño sano recomendaciones de salud cuyo impacto es de difícil medición. Este trabajo demuestra que la estimulación de la lectura compartida entre padres y niños, es beneficiosa en el desarrollo del lenguaje del niño deambulador. El impacto de la intervención estaría dado por la lectura en voz alta, por lo que tendríamos que recomendarla. Las guías anticipatorias serían herramientas útiles. En el trabajo se donaron libros específicos para cada edad. Si bien este es un método difícil de implementar, se podría suplir con la recomendación de títulos seleccionados cuidadosamente por especialistas en esta área.
Sería necesario un seguimiento longitudinal de las habilidades en el lenguaje ,el rendimiento en el jardín y en la escuela en estos niños para determinar la persistencia en el tiempo de estas adquisiciones.

Este artículo pone en evidencia que una recomendación, que por sentido común históricamente el pediatra realizaba en la consulta de niño sano, es útil en el desarrollo del niño, y propone realizarla a edades aún mas tempranas de lo que acostrumbábamos a hacerla.

Quedan sin medir otros efectos beneficiosos en la relación entre padres e hijos y para el niño, que surgen de compartir tiempo y actividades.

\section{Dr. Julio N. Busaniche [ Departamento de Pediatría. Hospital Italiano de Buenos Aires ]}

\section{Referencias}

1. Needlman R, Freid L, Morley D. Clinic-based intervention to promote literacy: a pilot study. Am J Disease Child. 1991;145:881-8842)

2. High P, Hopmann M, Lagasse L. Child centered literacy orientation: a form of social capital? Pediatrics 1999; 103(4).

3. Golova N, Alario A Vivier P. Literacy promotion for hispanics families in a rimary care setting: a randomized controlled trial Pediatric 1999:103.993-997.

4. Kagan J. The role of parents in children's psycological development. Pediatrics. 1999;104(suppl):164-167. 